University of Nebraska - Lincoln

DigitalCommons@University of Nebraska - Lincoln

Faculty Papers and Publications in Animal

Science

Animal Science Department

$5-31-2005$

\title{
Biological responses to porcine respiratory and reproductive syndrome virus in pigs of two genetic populations
}

D. B. Petry

University of Nebraska-Lincoln

J. W. Holl

University of Nebraska-Lincoln

J. S. Weber

University of Nebraska-Lincoln

Alan R. Doster

University of Nebraska-Lincoln, adoster1@unl.edu

Fernando A. Osorio

University of Nebraska-Lincoln, fosorio1@unl.edu

See next page for additional authors

Follow this and additional works at: https://digitalcommons.unl.edu/animalscifacpub

Part of the Animal Sciences Commons

Petry, D. B.; Holl, J. W.; Weber, J. S.; Doster, Alan R.; Osorio, Fernando A.; and Johnson, R. K., "Biological responses to porcine respiratory and reproductive syndrome virus in pigs of two genetic populations" (2005). Faculty Papers and Publications in Animal Science. 68.

https://digitalcommons.unl.edu/animalscifacpub/68

This Article is brought to you for free and open access by the Animal Science Department at DigitalCommons@University of Nebraska - Lincoln. It has been accepted for inclusion in Faculty Papers and Publications in Animal Science by an authorized administrator of DigitalCommons@University of Nebraska - Lincoln. 


\section{Authors}

D. B. Petry, J. W. Holl, J. S. Weber, Alan R. Doster, Fernando A. Osorio, and R. K. Johnson 


\title{
Biological responses to porcine respiratory and reproductive syndrome virus in pigs of two genetic populations ${ }^{1,2}$
}

\author{
D. B. Petry ${ }^{3}$, J. W. Holl ${ }^{3}$, J. S. Weber ${ }^{3}$, A. R. Doster ${ }^{4}$, F. A. Osorio ${ }^{4}$, and R. K. Johnson ${ }^{5}$ \\ Department of Animal Science, University of Nebraska, Lincoln 68583-0908
}

\begin{abstract}
One hundred pigs from the NE Index Line (NEI) and 100 Hampshire-Duroc cross pigs (HD) were inoculated intranasally with porcine respiratory and reproductive syndrome virus (PRRSV 97-7895 strain) at $26 \mathrm{~d}$ of age to determine whether genetic variation in response to PRRSV exists. An uninfected littermate to each infected pig served as a control. Pigs were from 163 dams and 83 sires. Body weight and rectal temperature were recorded, and blood samples were drawn from each pig on $\mathrm{d} 0$ before inoculation and on $\mathrm{d} 4,7$, and 14 after inoculation. Pigs were sacrificed on d 14. Lung and bronchial lymph nodes were collected, placed in optimal cutting temperature compound, and frozen at $-80^{\circ} \mathrm{C}$. The presence of PRRSV in serum and in lung tissue and bronchial lymph nodes was determined by isolation in cell culture. The presence of antibodies in serum collected on d 14 was determined by a commercial ELISA test. Lung tissue was examined microscopically and scored for incidence and severity of lesions (score of 1 to $3 ; 1=$ no or few lesions, and $3=$ severe interstitial pneumonia). Data were analyzed with a mixed model that included random sire and dam effects. The interaction of line $\times$ treatment was significant $(P$
\end{abstract}

$<0.001$ ) for weight change and rectal temperature. Uninfected HD pigs gained $0.67 \mathrm{~kg}$ more from d 0 to 14 and averaged $0.32^{\circ} \mathrm{C}$ higher rectal temperature than uninfected NEI pigs $(P<0.001)$, whereas infected NEI pigs gained $0.34 \mathrm{~kg}$ more and had $-0.54^{\circ} \mathrm{C}$ lower temperature than infected HD pigs $(P<0.001)$. Viremic titer (cell culture infectious dose $50 \% / \mathrm{mL})$ was greater $(P<$ $0.05)$ in HD than NEI at d $4\left(10^{4.52}\right.$ vs. $\left.10^{4.22}\right), 7\left(10^{4.47}\right.$ vs. $\left.10^{3.99}\right)$, and $14\left(10^{3.49}\right.$ vs. $\left.10^{3.23}\right)$. Viral titer loads in lung $(P=0.11)$ and bronchial lymph nodes tended $(P=$ $0.07)$ to be greater in HD than NEI pigs. Antibody signal-to-positive (S/P) ELISA ratios in infected pigs ranged from 0.18 to 3.38 , and $88 \%$ had levels $\geq 0.40$, which is the positive threshold for this ELISA. The S/ $\mathrm{P}$ range in uninfected pigs was 0 to 1.11 , and $99 \%$ had levels $\leq 0.40$. Mean $\mathrm{S} / \mathrm{P}$ ratio for infected pigs was 0.23 units higher in HD than in NEI $(P<0.001)$. The HD pigs had a greater incidence of interstitial pneumonia and 0.65 higher mean lesion scores than NEI pigs $(P<$ 0.001). In summary, responses of pigs of the two lines to infection with PRRSV differed, indicating that underlying genetic variation existed.

Key Words: Biological Indicators, Genetic Variation, Virus

(C)2005 American Society of Animal Science. All rights reserved.

J. Anim. Sci. 2005. 83:1494-1502

\section{Introduction}

Considerable evidence for genetic variation in pigs in response to pathogens or to challenges to the immune system exists (Duchet-Suchaux et al., 1991; Mallard et

\footnotetext{
${ }^{1}$ Published as Paper No. 14791, Journal Ser., Nebraska Agric. Res. Div., Univ. of Nebraska, Lincoln 68583-0908.

${ }^{2}$ This research was approved by the Univ. of Nebraska Institutional Animal Care and Use Committee (IACUC \#00-02-007).

${ }^{3}$ Current address: A218 Animal Sciences, Univ. of Nebraska, Lincoln 68583-0908.

${ }^{4}$ Current address: Dept. of Vet. Biom. Sci., Univ. of Nebraska, Lincoln 68583-0907.

${ }^{5}$ Correspondence: A218 Animal Sciences (phone: 402-472-6404; fax: 402-472-6362; e-mail: rjohnson5@unl.edu).

Received October 27, 2004.

Accepted April 1, 2005.
}

al., 1998; Wilkie and Mallard, 1999; Henryon et al., 2002). Selection directly on genotypes for genes coding resistance/susceptibility to certain pathogens can be practiced. For example, susceptibility to colonization by F18-bearing Escherichia coli is controlled by a dominant allele and resistance by a recessive allele (Bertschinger et al., 1993) and a PCR-restriction fragment length polymorphism test for the mutation in the encoding gene is available (Meijerink et al., 1997); however, markers for genes involved in immune responses to most diseases do not exist. Selection for resistance to such diseases using quantitative methods is generally not feasible. Quantification of health in breeding populations is difficult (Mallard et al., 1992; Wilkie and Mallard, 1998), and little is known about the relative magnitude of genetic and environmental variation for most diseases. 
Porcine reproductive and respiratory syndrome virus (PRRSV) is currently the most economically significant infectious disease affecting pigs (Holck and Polson, 2003). It infects pulmonary alveolar macrophages and causes severe interstitial pneumonia (Molitor et al., 1997; Thanawongnuwech et al., 1997). Infection often leads to immunosuppression (Done and Paton, 1995; Meier et al., 2003), and it also may cause abortion, premature farrowing, stillborn pigs, and mummified pigs.

It is important to identify traits that differentiate animals that respond differently to pathogens and to build the phenotypic and genotypic records to quantify genetic variation among animals and identify the genes involved. To study the effects of PRRSV infection, pigs of two different genetic populations were infected with PPRSV. Several biological responses were recorded with the objective of determining whether genetic variation in responses to PRRSV exists.

\section{Materials and Methods}

\section{Population}

A total of 400 pigs were used in the experiment: 200 pigs from the NE Index line (NEI), a Large WhiteLandrace composite population that had been selected for increased litter size for 20 generations, and 200 from a cross of Hampshire and Duroc lines (HD) that had been selected for rate and efficiency of lean growth. Details of the selection history in Line NEI are given by Johnson et al. (1999), and responses in reproduction traits through Generation 19 are reported by Petry et al. (2004).

Line NEI pigs were born in the University of Nebraska swine research herd, whereas HD pigs were obtained from a commercial farm. Neither farm had experienced PRRSV. In addition, before initiation of the experiment, pigs from both herds had tested negative for the presence of PRRSV by PCR methods and for PRRSV serum antibodies by the ELISA test (IDDEX Labs, West Brook, ME). Pigs for this study were selected at random from available litters. Two pigs of the same sex from as many different litters and families as possible, representing a total of 83 sires and 163 dams, were sampled to broadly represent the populations. The experiment was conducted in two replicates within each of two seasons, with 50 pigs per breed in each year-season-replicate for a total of 200 infected pigs and 200 uninfected pigs.

Pigs were transported from their farm of origin at an average age of $23 \mathrm{~d}$ to the University of Nebraska Veterinary and Biomedical Sciences Animal Research Facility and were placed in environmentally controlled rooms with 25 pigs per room. Each room contained one pen of pigs of each line with 12 to 13 pigs per pen. Within each replication, one room was assigned randomly for treatment, and the pigs in it were inoculated intranasally with PRRSV. Pigs in the other isolated room, which were littermates to those in the infected room, served as controls. After a 3-d acclimation period, pigs in rooms designated for infection were inoculated with a $2-\mathrm{mL}$ dose of $10^{5}$ cell culture infectious dose $50 \% / \mathrm{mL}$ (CCID $_{50}$ ) of PRRSV Strain 97-7985 (Osorio et al., 2002) by applying $1 \mathrm{~mL}$ per nostril. Based on the temporal sequence of events on infection of a pig with PRRSV described by Osorio (2002), 0, 4, 7 and $14 \mathrm{~d}$ were selected as data collection points to capture the maximum amount of viral replication in vivo.

At $\mathrm{d} 0$, Line NEI pigs were $28 \mathrm{~d}$ old $(\mathrm{SD}=8.1 \mathrm{~d})$ and weighed $5.06 \mathrm{~kg}(\mathrm{SD}=2.54 \mathrm{~kg})$, whereas HD pigs were $23.7 \mathrm{~d}$ old $(\mathrm{SD}=6.3 \mathrm{~d})$ and weighed $5.38 \mathrm{~kg}(\mathrm{SD}=2.17$ $\mathrm{kg}$ ). Pigs were given ad libitum access to water and feed. A corn-soybean meal diet formulated on an as-fed basis to contain $21 \% \mathrm{CP}, 1.20 \%$ lysine, $0.80 \% \mathrm{Ca}, 0.70 \%$ $\mathrm{P}$, and $3.4 \mathrm{Mcal} / \mathrm{kg}$ of $\mathrm{ME}$ was fed throughout the trial. Temperature in the rooms was maintained between 26 and $29^{\circ} \mathrm{C}$.

\section{Traits Measured}

Body temperature by rectal probe, BW, and blood draws of all pigs were collected and recorded just before inoculation (d 0) and 4, 7, and $14 \mathrm{~d}$ after inoculation. On d 14, all pigs were sacrificed, necropsy was performed, and samples of lung, bronchial lymph node, and spleen were collected and stored at $-80^{\circ} \mathrm{C}$ for future use. Level of viremia $\left(\mathrm{CCID}_{50} / \mathrm{mL}\right)$ was measured in each pig by microtitration on cultures of MARC 145 cells, as well as in the lung and bronchial lymph node tissue collected at necropsy. Serum samples collected on d 14 from pigs infected with PRRSV and their uninfected littermates were analyzed with an ELISA (IDDEX Labs) test to determine the level of PPRSV antibody in infected pigs, expressed as sample-to-positive $(\mathbf{S} / \mathbf{P})$ ratio as defined in the ELISA kit, and to test for possible cross contamination in uninfected pigs.

Lungs were scored for the presence of pneumonia (yes $=1$ or no $=0$ ). Representative sections of the left cardiac lobe of the lung of each pig were placed in $10 \%$ neutral buffered formalin, fixed for $24 \mathrm{~h}$, processed, embedded in paraffin, sectioned into $5-\mu \mathrm{m}$ pieces, and stained with hemoxylin and eosin. Sections of lung were examined by light microscopy and scored subjectively on a scale of 1 to 3 (Figure 1). Lungs receiving a score of 1 had no lesions or had mild multifocal interstitial pneumonia characterized by mild infiltration of the alveolar interstitium by lymphocytes, plasma cells, and macrophages. A score of 2 was given to lung sections that had moderate interstitial infiltration of mononuclear cells that caused diffuse alveolar interstitial thickening involving less than $50 \%$ of the area of the section. A score of 3 was given to lung sections that had greater than 50\% involvement of severe interstitial pneumonia. Alveolar septae in infected lungs were thickened due to mononuclear cell infiltration. Necrosis of Type-I pneumocytes was accompanied by Type-2 pneumocyte hyperplasia and hypertrophy. In addition, if present, 


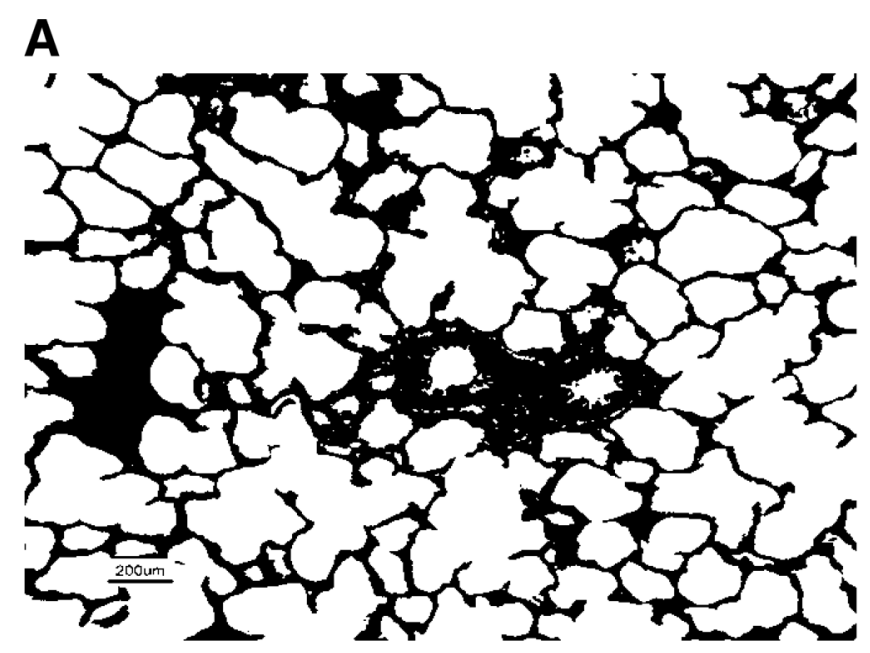

\section{B}
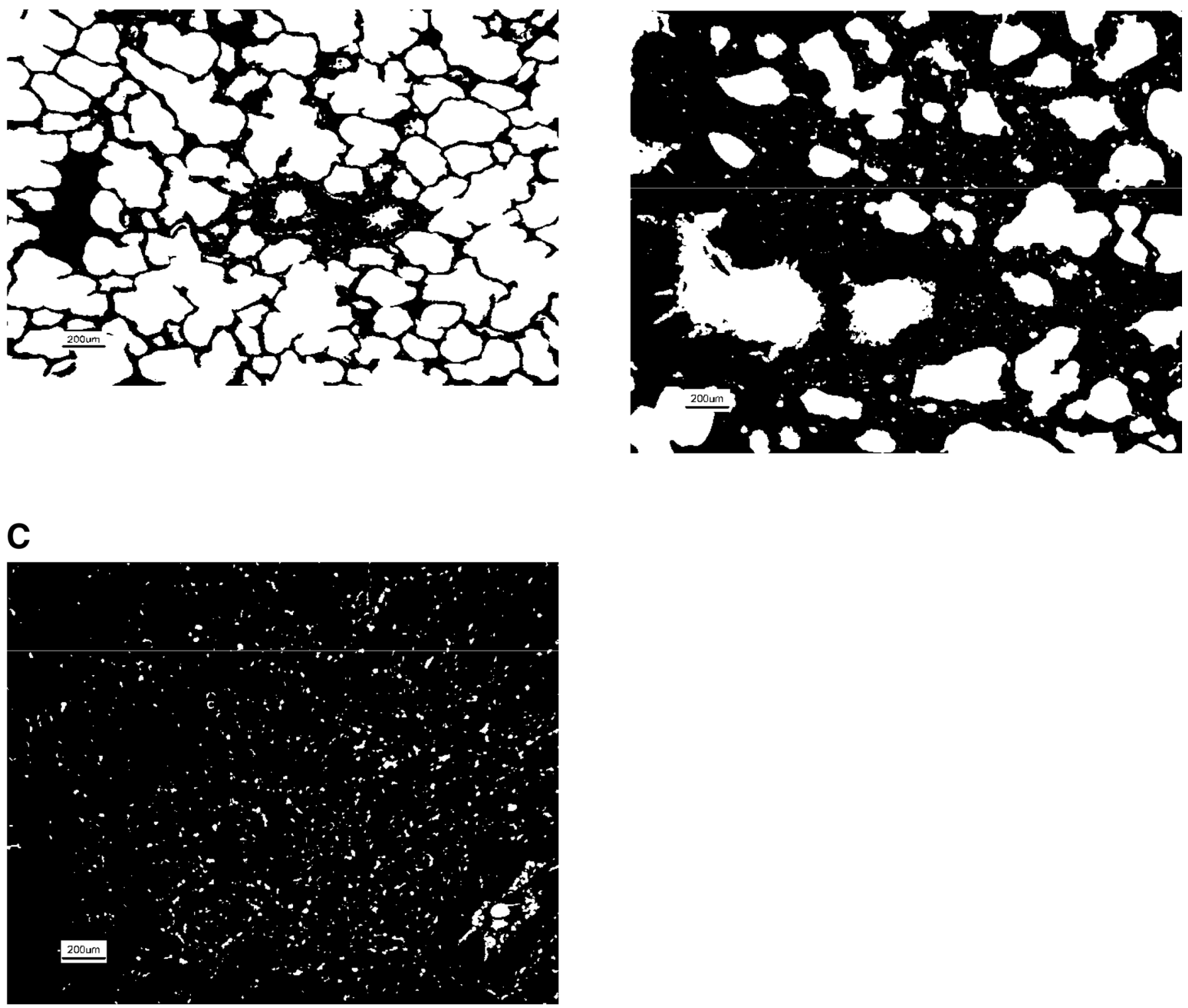

Figure 1. A) Score I; normal lung. Alveoli are distended with air and no interstitial is thickening noted. B) Score II; Diffuse interstitial thickening due to mononuclear cell infiltration is noted. Some alveoli are recognizable. C) Score III; Diffuse interstitial thickening accompanied by Type-2 cell hyperplasia and hypertrophy. Alveoli are not readily discernable.

lesions suggestive of Mycoplasma hyopneumonae and infectious bacterial pneumonia were recorded for each pig.

\section{Statistical Analyses}

All analyses were performed with SAS software (SAS Inst., Inc., Cary, NC). Viral titer levels were recorded on an exponential scale and normalized by analyzing exponents. Weight change was calculated as the difference in weight between each period (d 0 to 4 , d 4 to 7 , and $d 7$ to 14). Rectal temperature, weight change, and viremia were analyzed using a mixed model with yearseason-replication, line, treatment, period, and all com- binations of interactions as fixed effects. Sire, dam within sire, and pig within dam within sire were treated as random effects. Age was fitted as a covariate to adjust records of all pigs in each period to the same age. The fixed effect of treatment was omitted from the model for viremia because it was not measurable in control pigs.

Viral load in the lung and bronchial lymph node, ELISA ratio, and lung histology scores recorded at necropsy were analyzed with the same model, except that period was removed from the fixed effects, and pig within dam within sire was removed from the random effects. Correlations among traits were calculated within period and between periods with the PROC MANOVA procedure, including line, replication, and inter- 


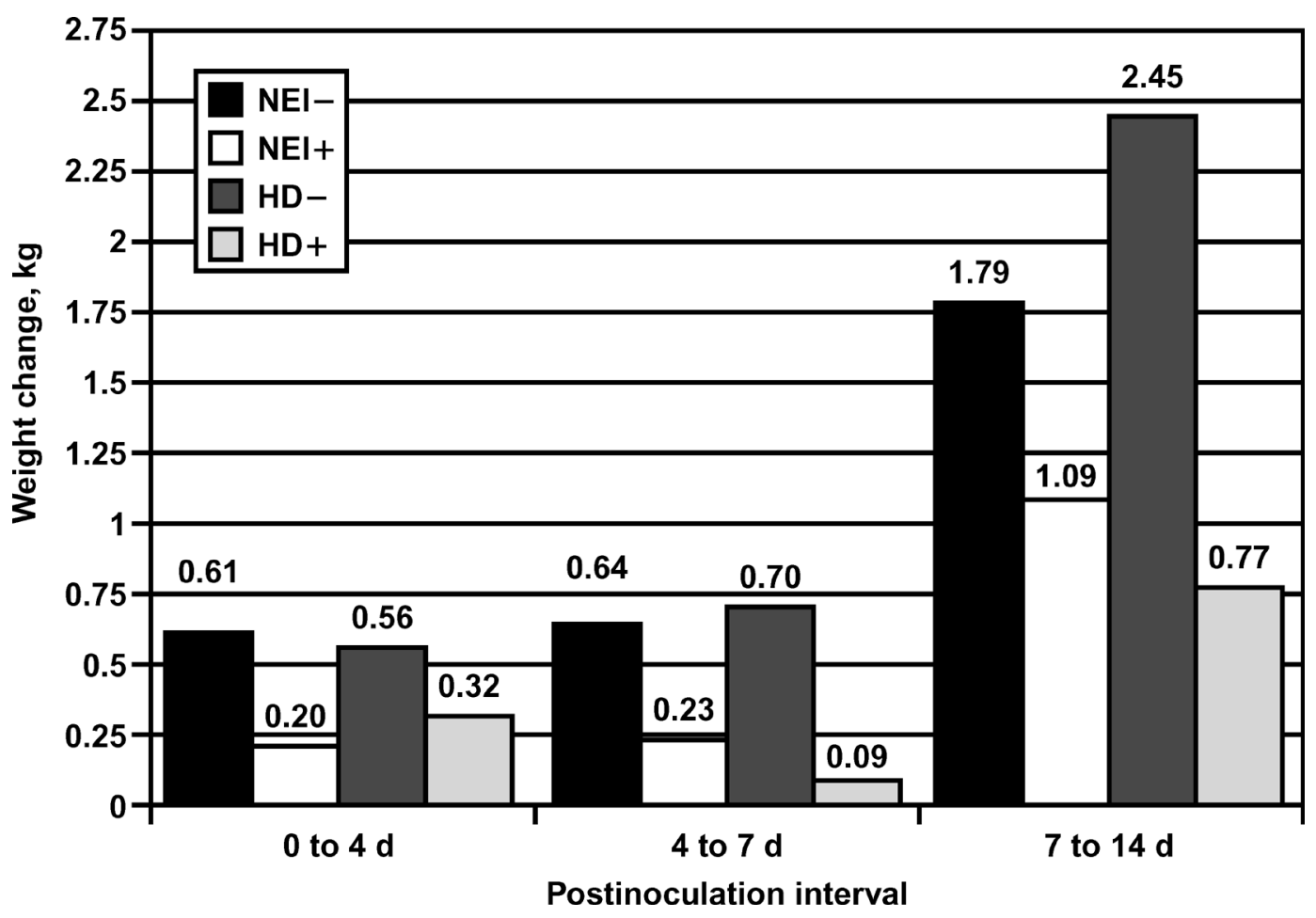

Figure 2. Weight change from d 0 to $4, \mathrm{~d} 4$ to 7 , and $\mathrm{d} 7$ to 14 for Index (NEI) and Hampshire-Duroc cross (HD) pigs without $(-)$ and with $(+)$ porcine respiratory and reproductive syndrome virus infection (treatment, line $\times$ treatment, and line $\times$ treatment $\times$ interval; $P<0.001$; SEM $=0.05$ ).

action in the model, separately for infected and uninfected pigs, to determine relationships among traits.

\section{Results}

Pigs infected with PRRSV gained less weight $(P<$ $0.001)$ during each interval than their uninfected littermates (Figure 2), but the pattern of response during the three intervals was different between lines (line $\times$ treatment and line $\times$ treatment $\times$ interval; $P<0.001$ ). Uninfected HD pigs gained more rapidly from $d 4$ to 7 $(0.06 \pm 0.08)$ and from $d 7$ to $14(0.66 \pm 0.08)$ than NEI pigs; however, NEI pigs infected with PRRSV gained more from $\mathrm{d} 4$ to $7(0.14 \pm 0.08)$ and from $\mathrm{d} 7$ to $14(0.32$ \pm 0.08 ) than infected HD pigs.

Rectal temperature (Figure 3) was affected by line, treatment, and interactions (line, treatment, line $x$ treatment, and line $\times$ treatment $\times$ day; $P<0.001$ ). Infected pigs of each genetic line had higher rectal temperatures on $\mathrm{d} 4,7$, and 14 than their uninfected littermates. Overall, HD pigs had higher temperature than NEI pigs $(P<0.001)$, and mean temperature increased in both lines from d 0 to $14(P<0.001)$. The pattern of response for uninfected pigs was similar in both lines; however, the response in infected littermates was different. Temperatures increased more rapidly in infected HD pigs, especially from d 0 to 4 , and remained higher to d 14. Rectal temperatures of infected pigs of both lines seemed to peak on $\mathrm{d}\left(39.40^{\circ} \mathrm{C}\right.$ for NEI and $40.15^{\circ} \mathrm{C}$ for $\mathrm{HD}$ ) and then decrease slightly on $\mathrm{d} 14$ $\left(39.34^{\circ} \mathrm{C}\right.$ for NEI and $39.88^{\circ} \mathrm{C}$ for $\left.\mathrm{HD}\right)$.

Mean ELISA S/P ratios of infected pigs on d 14 were 1.30 in HD pigs and 1.07 in NEI pigs $(P<0.001)$. As described in the test kit, pigs with an ELISA ratio of 0.40 or greater should be considered to be positive for antibodies in the serum to PRRSV. The ELISA ratios of infected pigs ranged from 0.18 to 3.38 , and 176 out of 200 pigs had ratios $\geq 0.40$. Ratios for uninfected littermates ranged from 0 to 1.11 , and 199 out of 200 pigs had ratios $\leq 0.40$.

Mean viremia level is illustrated in Figure 4. Viremia could be recorded only in blood drawn from infected pigs at $d 4,7$, and 14 . Values in the graph are base 10 logarithms, so differences in exponents represent exponentially greater differences in number of $\mathrm{CCID}_{50} /$ $\mathrm{mL}$. For example, the coefficients of 4.22 and 4.52 for NEI and HD pigs at d 4, respectively, represent a twofold difference in number of $\mathrm{CCID}_{50} / \mathrm{mL}$ of blood. Viral titer level was greater in HD than NEI pigs on d 4, 7 , and $14(P<0.001)$; line $\times$ day interaction was not important $(P>0.30)$. Viral load recorded in lung tissue and bronchial lymph nodes is illustrated in Figure 5. The HD pigs tended to have higher PRRSV titer in the lung $(0.41 \pm 0.14, P=0.11)$ and the bronchial lymph nodes $(0.51 \pm 0.14, P=0.07)$ than NEI pigs.

Mean pneumonia scores for infected pigs were greater for HD than NEI (1.92 vs. $1.27 ; P<0.001)$. Lesions were observed in a few uninfected pigs, but the incidence was very low for both NEI and HD pigs. 


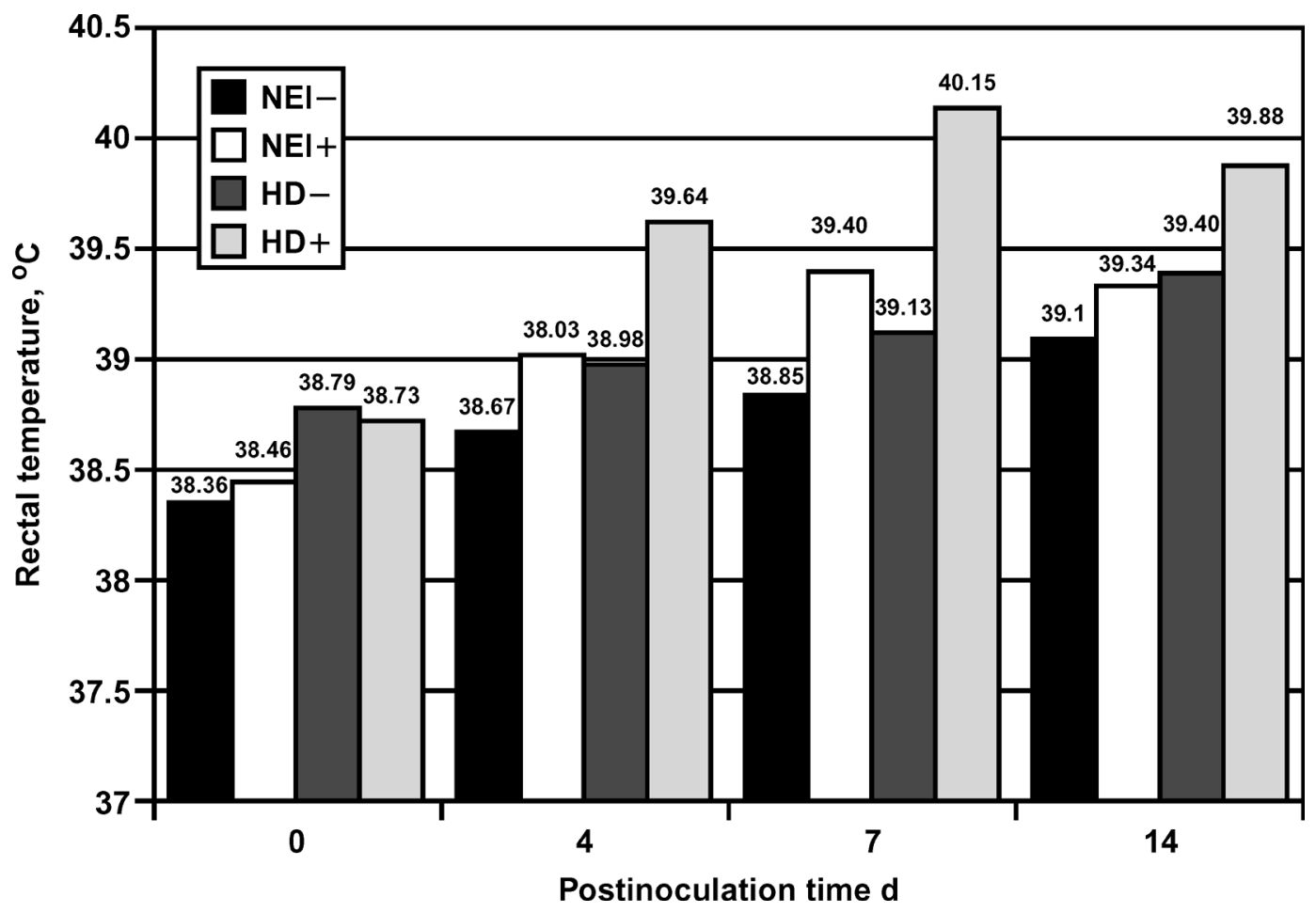

Figure 3. Rectal temperature $\left({ }^{\circ} \mathrm{C}\right)$ at $\mathrm{d} 0,4,7$, and 14 after infection for uninfected $(-)$ and infected (+) Index (NEI) and Hampshire-Duroc (HD) pigs (line, treatment, line $\times$ treatment, line $\times$ treatment $\times$ day; $P<0.001 ;$ SEM $=0.10$ ).

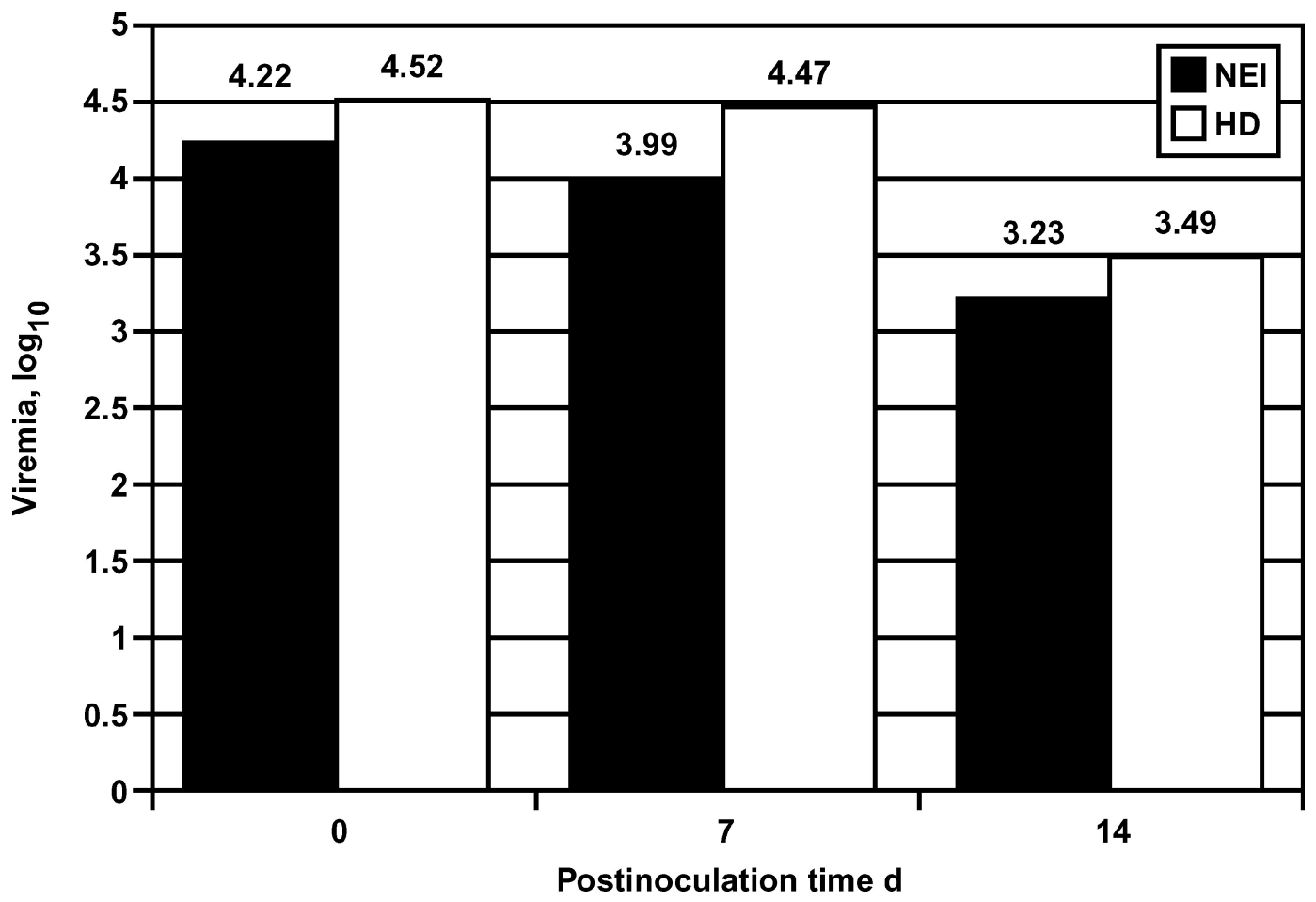

Figure 4. Viremia titer, expressed as $\log _{10} \mathrm{CCID}_{50} / \mathrm{mL}$, (cell culture infectious dose $50 \% / \mathrm{mL}$ ) in serum of Index (NEI) and Hampshire-Duroc cross (HD) pigs at 4, 7, and $14 \mathrm{~d}$ after infection with porcine respiratory and reproductive syndrome virus (line; $P<0.0001 ; \mathrm{SEM}=0.07$ ). 


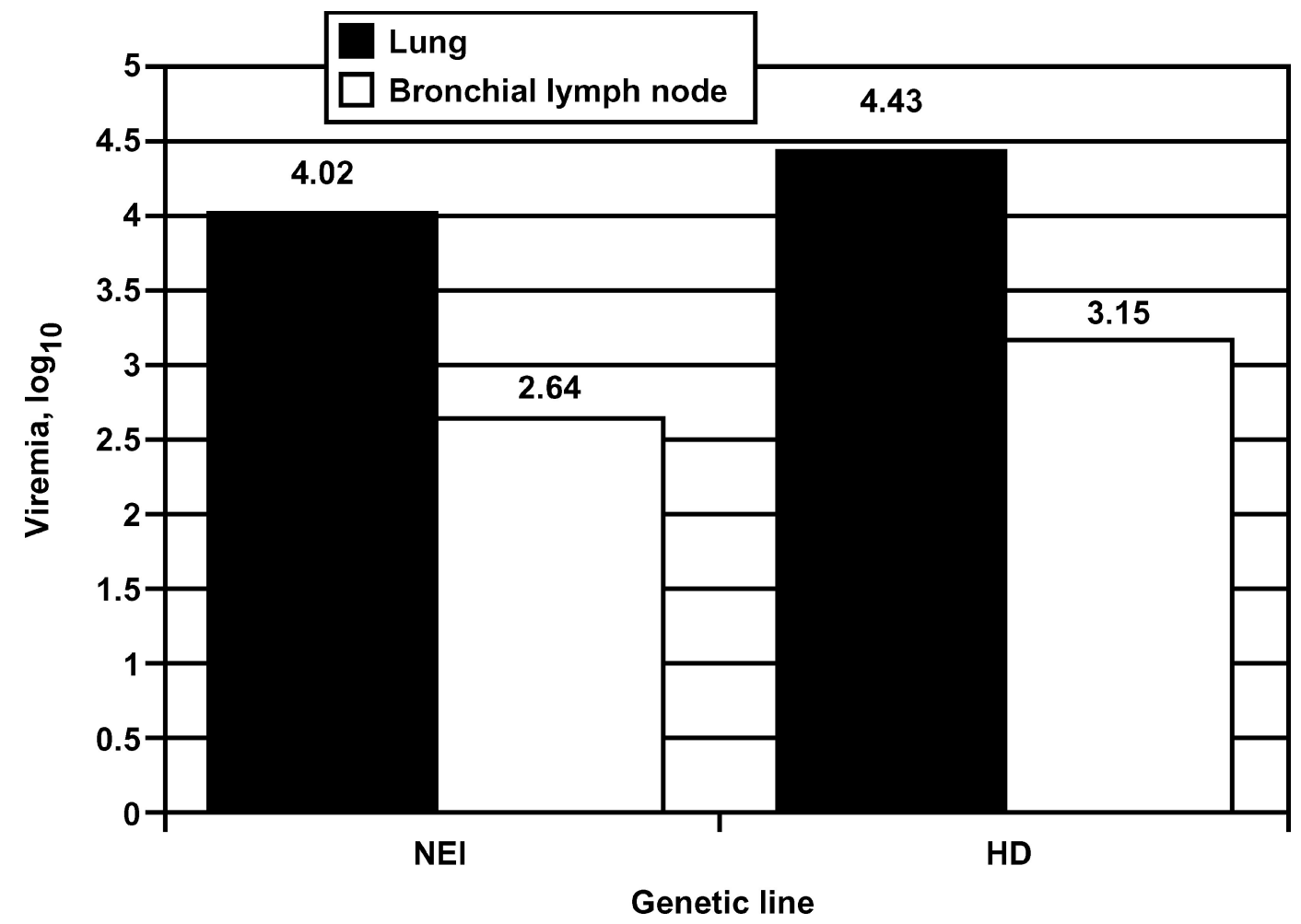

Figure 5. Viral titer, expressed as $\log _{10} \mathrm{CCID}_{50} / \mathrm{g}$, (cell culture infectious dose $50 \% / \mathrm{mL}$ ) of tissue, at $\mathrm{d} 14$ in the lung (line, $P=0.11$; SEM = 0.10) and bronchial lymph nodes (line; $P=0.07$; SEM = 0.09) of Index (NEI) and HampshireDuroc cross (HD) pigs infected with porcine respiratory and reproductive syndrome virus.

Correlations among weight changes in each period in uninfected pigs ranged from 0.30 to 0.50 , and correlations among temperatures recorded on different days ranged from 0.19 to 0.37 (Table 1). Correlations among weight changes and body temperatures also were positive, ranging from 0.13 to 0.31 .

Correlations among weight changes and temperatures in infected pigs tended to be lower and were less consistent across periods than in uninfected pigs (Table 2 ). A weak, negative correlation ( -0.11 ) between weight change from $\mathrm{d} 0$ to 4 and weight change from $\mathrm{d} 4$ to 7 existed, whereas the correlation between weight change from d 0 to 4 and weight change from $d 7$ to 14 was weak but positive (0.24). The correlations of weight change from $\mathrm{d} 7$ to 14 with weight change from $\mathrm{d} 0$ to 4 and with weight change from d 4 to 7 were similar in infected and uninfected pigs. Correlations among temperatures in different periods ranged from 0.04 to 0.30 , and correlations among weight changes and temperatures ranged from -0.02 to 0.28 .

Viremia and weight change tended to be negatively correlated; however, correlations ranged from -0.46 to 0.15 , indicating relatively weak associations. Viremia and temperature were essentially uncorrelated. Viremia at the different periods was positively related, but again, the associations were not strong, ranging from 0.06 to 0.20 . Associations of lung lesion scores and ELISA ratios with all other traits were very low.

Table 1. Correlations between body weight change $(\mathrm{kg})$ from $\mathrm{d} 0$ to $4\left(\mathrm{WC}_{0-4}\right), \mathrm{d} 4$ to 7 $\left(\mathrm{WC}_{4-7}\right)$, and $\mathrm{d} 7$ to $14\left(\mathrm{WC}_{7-14}\right)$ and rectal temperature $\left({ }^{\circ} \mathrm{C}\right)$ at $\mathrm{d} 0(\mathrm{~T} 0), 4(\mathrm{~T} 4), 7(\mathrm{~T} 7)$, and 14 (T14) in uninfected pigs

\begin{tabular}{lcccccc}
\hline \hline Trait & $\mathrm{WC}_{4-7}$ & $\mathrm{WC}_{7-14}$ & $\mathrm{~T} 0$ & $\mathrm{~T} 4$ & $\mathrm{~T} 7$ & $\mathrm{~T} 14$ \\
\hline $\mathrm{WC}_{0-4}$ & $0.30^{\mathrm{a}}$ & 0.42 & 0.21 & 0.21 & 0.17 & 0.13 \\
$\mathrm{WC}_{4-7}$ & & 0.50 & 0.31 & 0.31 & 0.26 & 0.20 \\
$\mathrm{WC}_{7-14}$ & & 0.23 & 0.24 & 0.20 & 0.28 \\
T0 & & & 0.26 & 0.24 & 0.19 \\
T4 & & & & 0.37 & 0.21 \\
T7 & & & & & 0.37 \\
\hline
\end{tabular}

${ }^{\text {a } C o r r e l a t i o n s ~ g r e a t e r ~ t h a n ~} 0.15=P<0.05$; greater than $0.20=P<0.01$. 
Table 2. Correlations among traits recorded in pigs infected with porcine respiratory and reproductive syndrome virus

\begin{tabular}{|c|c|c|c|c|c|c|c|c|c|c|c|c|c|c|}
\hline Trait $^{\mathrm{a}}$ & $\mathrm{WC}_{4-7}$ & $\mathrm{WC}_{7-14}$ & T0 & $\mathrm{T} 4$ & $\mathrm{~T} 7$ & $\mathrm{~T} 14$ & $\mathrm{~V} 4$ & V7 & V14 & LV & LYV & $\mathrm{P}$ & $\mathrm{L}$ & $\mathrm{E}$ \\
\hline $\mathrm{WC}_{4-7}$ & & 0.39 & 0.09 & 0.08 & -0.02 & 0.09 & -0.13 & -0.10 & -0.27 & -0.09 & -0.01 & -0.10 & 0.01 & 0.14 \\
\hline T0 & & & & 0.04 & 0.10 & 0.16 & -0.06 & -0.07 & -0.07 & -0.02 & -0.01 & 0.02 & -0.01 & 0.09 \\
\hline $\mathrm{T} 4$ & & & & & 0.29 & 0.24 & -0.04 & 0.08 & -0.23 & -0.13 & 0.03 & -0.12 & -0.09 & 0.03 \\
\hline $\mathrm{T} 7$ & & & & & & 0.30 & 0.00 & -0.05 & -0.15 & -0.02 & -0.02 & -0.14 & 0.04 & 0.11 \\
\hline V7 & & & & & & & & & 0.20 & 0.11 & 0.16 & 0.15 & 0.18 & -0.02 \\
\hline V14 & & & & & & & & & & 0.27 & 0.26 & 0.02 & 0.00 & -0.11 \\
\hline $\mathrm{LV}$ & & & & & & & & & & & 0.44 & 0.07 & 0.24 & -0.17 \\
\hline LYV & & & & & & & & & & & & 0.00 & 0.02 & -0.09 \\
\hline $\mathrm{P}$ & & & & & & & & & & & & & 0.46 & -0.01 \\
\hline $\mathrm{L}$ & & & & & & & & & & & & & & -0.03 \\
\hline
\end{tabular}

${ }^{\mathrm{a}} \mathrm{WC}_{0-4}, \mathrm{WC}_{4-7}$, and $\mathrm{WC}_{7-14}=$ weight change from d 0 to $4, \mathrm{~d} 4$ to 7 , and $\mathrm{d} 7$ to 14 , respectively; $\mathrm{T} 0, \mathrm{~T} 4, \mathrm{~T} 7, \mathrm{~T} 14=$ rectal temperature at $\mathrm{d}$ 0 before infection and on $\mathrm{d} 4,7$, and 14 after treatment, respectively; V4, V7, and V14 = viremia in serum collected at d 4, 7, and 14, respectively; LV and LYV = viremia in lung and lymph, respectively, collected at necropsy on d 14; $\mathrm{P}=$ incidence of interstitial pneumonia, scored as 0 or $1 ; \mathrm{L}=$ severity of lung lesions, scored as 1 to 3 ; and $\mathrm{E}=\mathrm{ELISA}$ antibody ratio.

${ }^{\mathrm{b}}$ Correlations greater than $0.15=P<0.05$; greater than $0.20=P<0.01$.

\section{Discussion}

Line differences and line $\times$ treatment interactions across days are evidence that genetic variation in the mechanisms involved in immune responses to PRRSV exists. Higher body temperature, decreased growth rate and greater viremia in serum, lung, and lymph in HD than NEI pigs indicates that NEI pigs were more resistant to PRRSV than HD pigs. Halbur et al. (1998), using breeds unrelated to those in this study, infected pigs with PRRSV and also found breed differences for ELISA ratios, ADG, and in severity of PRRSV-induced lesions in the lung. A preliminary examination of allelic variation in PRRSV-response genes revealed the presence of SNP in 26 of 52 genes (Hawken et al., 2001). This variability may be associated with genetic variability in the immune response of pigs to PRRSV.

There is little additional direct evidence for genetic variation in pigs in response to PRRSV; however, Mallard et al. (1998) and Wilkie and Mallard (1999) reported results of eight generations of selection for antibody- and cell-mediated immune responses in pigs. High, low, and control lines diverged for growth rate, antibody response to various antigens, and response to Mycoplasma hyorhinis. They concluded that genetic variation in response to certain antigens and to $M$. hyorhinis exists. The genetic variation was polygenic, regulating both innate resistance and acquired immunity. To evaluate the feasibility of selecting indirectly for immune response, Henryon et al. (2002) estimated heritabilities of number and distribution of leukocytes in samples of blood from pigs in a performance test station. Estimates of heritabilities were $25 \%$ for the number of leukocytes and 22 to $29 \%$ for number of different types of leukocytes. Specific diseases were not reported, so the reliability of selecting on number or type of leukocytes could not be determined. In a review, Vissher et al. (2002) reported evidence for substantial genetic varia- tion between pigs and concluded that there is the possibility for genetic improvement of the immune capacity to respond to pathogens.

The PRRSV mainly targets alveolar macrophages of pulmonary cells (Osorio, 2002). Due to rapid replication in these cells, clinical signs of PRRSV are evident in the early postinoculation period. In this study, incidence of lesions in lungs of infected pigs at d 14 was much greater than in control pigs. Lesions in control pigs were suggestive of slight interstitial pneumonia not associated with PRRSV; the increase in infected pigs represented PRRSV-induced lesions. The direct effect of PRRSV is apoptosis of infected macrophages. Cytokines released by infected macrophages also cause apoptosis in uninfected bystander cells.

The PRRSV causes immunosuppression, resulting in increased susceptibility to secondary infections (Thanawongnuwech et al., 2000; Feng et al., 2001). Because of the relatively high level of biological security measures used, it is unlikely that other pathogens were introduced during the experiment; however, HD and NEI pigs came from two different farms and were likely exposed to different pathogens before the experiment. Although infected pigs of the two lines were in one room together and their uninfected littermates were together in another room, within a room, pigs of the two lines were not commingled in the same pen. Infected HD pigs had a higher incidence of lesions attributed to mycoplasma (22 vs. six cases) and bacteria (one vs. zero cases) in the lungs than uninfected HD pigs. Infected NEI pigs also had a higher incidence of lesions due to mycoplasma (28 vs. eight cases) and bacteria (five vs. one case) in the lungs than uninfected NEI pigs. The proportions of cases of these two types of pneumonia were similar for NEI and HD pigs, but the lines could have been exposed to other secondary pathogens not monitored in this study. The observed line differences must therefore be attributed jointly to the direct effects 


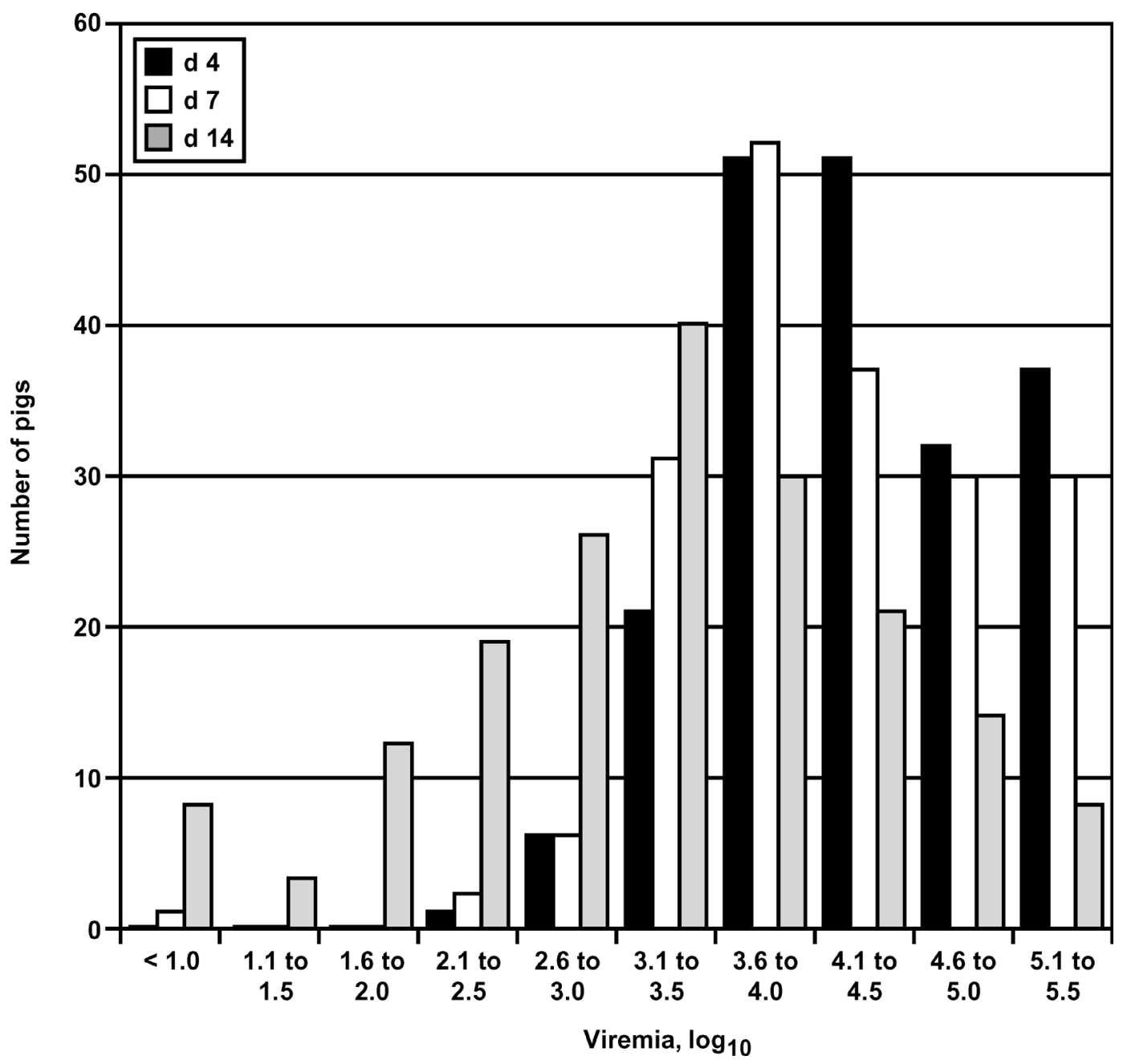

Figure 6. Distribution of viremia, $\log _{10}$, at $d 4(n=199), 7(n=189)$, and $14(n=181)$ in serum of infected pigs across populations.

of PRRSV and possible effects of other secondary pathogens. In addition, younger pigs tend to develop more severe clinical signs of PRRSV (Rossow et al., 1994). Therefore, responses in older pigs of these lines may differ from those observed in this experiment.

In this study, considerable variation among pigs within both genetic lines in response to PRRSV existed for several traits. Nonetheless, the traits were not highly correlated (Table 2 ), indicating that the different traits measure somewhat different responses to PRRSV. Viral infectivity titration was used to measure the amount of PRRSV in serum and tissue. The distribution of viremia (virus in the serum) across all pigs is illustrated in Figure 6. Pigs in the right tail of the distribution replicated the virus at very high rates, as high as $10^{5.5} \mathrm{CCID}_{50} / \mathrm{mL}$, whereas those in the other tail had replication rates as low as $10^{0.7} \mathrm{CCID}_{50} / \mathrm{mL}$ of blood. High levels of viral load tended to be associated with low weight gain, lower rectal temperature, and increased incidence of lung lesions, but correlations among these variables were low (absolute values of correlations ranged from 0 to 0.46 ). There were pigs that replicated the virus at high rates and showed all the clinical symptoms of PRRSV. They grew slowly, had high body temperatures, and had gross and microscopic lung lesions typical of PRRSV infection. Other pigs with similar levels of viremia showed few symptoms of PRRSV. They gained weight at normal rates, had normal or only slightly elevated body temperatures, and had few lung lesions. Similarly, there were pigs in this sample with relatively low levels of viral load that showed symptoms typical of PRRSV, whereas others had few clinical signs suggestive of PRRSV infection.

\section{Literature Cited}

Bertschinger, H. U., M. Stamm, and P. Vogeli. 1993. Inheritance of resistance to oedema disease in the pig: experiments with an Escherichia coli strain expressing fimbriae 107. Vet. Microbiol. 35:79-89.

Done, S. H., and D. J. Patton. 1995. Porcine reproductive and respiratory syndrome: Clinical disease, pathology, and immunosuppression. Vet. Rec. 136:32-35.

Duchet-Suchaux, M. F., A. M. Bertin, and P. S. Menanteau. 1991. Susceptibility of Chinese Meishan and European Large White 
pigs to enterotoxigenic Escherichia coli strains bearing colonization factor K88, 987P, K99, or F41. Am. J. Vet. Res. 52:40-49.

Feng, W. H., S. M. Laster, and M. Tompkins. 2001. In utero infection by porcine reproductive and respiratory syndrome virus is sufficient to increase susceptibility of piglets to challenge with Streptococcus suis type II. J. Virol. 75:4889-4895.

Halbur, P., M. Rothschild, and B. Thacker. 1998. Differences in susceptibility of Duroc, Hampshire, and Meishan pigs to infection with a high-virulence strain (VR2385) of porcine reproductive and respiratory syndrome virus (PRRSV). J. Anim. Breed. Genet. 115:181-189.

Hawken, R. J., I. Alvarez, and C. Wang. 2001. SNP identification for swine immune response EST's using SSCP analysis. Abstract P340 in Proc. Plant Anim. Genome IX, San Diego, CA.

Henryon, M., H. R. Juul-Madsen, and P. Berg. 2002. Genetic variation for total and differential numbers of leukocytes in growing pigs. Comm. No. 13-02 in Proc. 7th World Cong. Genet. Appl. Livest. Prod., Montpellier, France.

Holck, J. T., and D. D. Polson. 2003. The Financial Impact of PRRS Virus. Pages 47-54 in PRRS Compendium Producer Edition. Natl. Pork Board, Des Moines, IA.

Mallard, B. A., B. N. Wilkie, B. W. Kennedy, J. Gibson, and M. Quinton. 1998. Immune responsiveness in swine: eight generations of selection for high and low immune response in Yorkshire pigs. Pages 257-264 in Proc. 6th World Congr. Genet. Appl. Livest. Prod., Armidale, Australia.

Mallard, B. A., B. N. Wilkie, B. W. Kennedy, and M. Quinton. 1992. Use of estimated breeding values in a selection index to breed Yorkshire pigs for high and low immune and innate resistance factors. Anim. Biotech. 3:257-280.

Meier, W., J. Galeota, F. A. Osorio, R. J. Husmann, W. M. Schnitzlein, and F. A. Zuckerman. 2003. Gradual development of the interferon-gamma response of swine to porcine reproductive and respiratory syndrome virus infection or vaccination. Virology 309:18-31.

Meijerink, E., R. Fries, P. Vogeli, J. Masabanda, G. Wigger, C. Stricker, S. Neuenschwander, H. U. Bertschinger, and G. Stranzinger. 1997. Two alpha(1,2) fucosyltransferase genes on porcine chromosome 6q11 are closely linked to the blood group inhibitor
(S) and Escherichia coli F18 receptor (ECF18R) loci. Mamm. Genome 8:736-741.

Molitor, T. W., E. M. Bautista, and C. S. Choi. 1997. Immunity to PRRSV: Double-edged sword. Vet. Microbiol. 55:265-276.

Osorio, F. A. 2002. Porcine reproductive and respiratory syndrome. Pages 105-112 in Proc. 17th IPVS Cong., Ames, IA.

Osorio, F. A., J. A. Galeota, E. Nelson, B. Brodersen, A. Doster, R. Wills, F. Zuckerman, and W. W. Laegreid. 2002. Passive transfer of virus-specific antibodies confers protection against reproductive failure induced by a virulent strain of porcine reproductive and respiratory syndrome virus and establishes sterilizing immunity. Virology 302:9-20.

Petry, D. B., and R. K. Johnson. 2004. Responses to 19 generations of litter size selection in the Nebraska Index line. I. Reproductive responses estimated in pure line and crossbred litters. J. Anim Sci. 82:1000-1006.

Rossow, K. D., E. M. Bautista, and S. M. Goyal. 1994. Experimental rorcine reproductive and respiratory syndrome virus infection in one-, four-, and ten-week-old pigs. J. Vet. Diagn. Invest. 63:3-12.

Thanawongnuwech, R., E. L. Thacker, and P. G. Halbur. 1997. Effect of porcine reproductive and respiratory syndrome virus (PRRSV) (isolate VR-2385) infection on bactericidal activity of porcine pulmonary intravascular macrophages (PIMs): In vitro comparisons with pulmonary alveolar macrophages (PAMs). Vet. Immunol. Immunopathol. 59:323-335.

Thanawongnuwech, R., G. B. Brown, and P. G. Halbur. 2000. Pathogenesis of porcine reproductive and respiratory syndrome virusinduced increased susceptibility in Streptococcus suis infection. Vet. Pathol. 37:143-152.

Vissher, A. H., L. L. Janss, T. A. Niewold, and K. H. de Greef. 2002. Disease incidence and immunological traits for the selection of healthy pigs. A review. Vet. Q. 1:29-34.

Wilkie, B. N., and B. A. Mallard. 1998. Multi-trait selection for immune response: A possible alternative strategy for enhanced livestock health and productivity. Pages 29-38 in Progress in Pig Science. J. Wiseman, ed. Nottingham Univ. Press, Nottingham, U.K.

Wilkie, B., and B. Mallard. 1999. Selection for high immune response: an alternative approach to animal health maintenance? Vet. Immunol. Immunopathol. 72:231-235. 